\title{
DELIMITAÇÃO DE REQUISITOS PROJETUAIS E METODOLOGIA DE PROJETO EM DESIGN, PARA O DESENHO UNIVERSAL E ACESSÍVEL MÓVEIS: UM RECORTE PARA ARMÁRIOS DE GUARDAR ROUPAS
}

\author{
Rita Caroline da Silva \\ Universidade do Estado da Bahia \\ rcaroline72@gmail.com \\ Suzi Maria Mariño \\ Universidade do Estado da Bahia \\ suzimarino@gmail.com \\ Carina Santos Silveira \\ Universidade do Estado da Bahia \\ carinassilveira@gmail.com
}

Resumo: Este trabalho tem como questionamento apurar, como é abordada a acessibilidade no projeto de móveis sob medida e a possibilidade de projeto e execução de armários para guardar roupa acessíveis e universal. Para Isso foi necessária uma investigação e coleta de informações a respeito do caso estudado tornando-o mais compreensível. O objetivo como resultado inicial a ser abordado neste artigo, apontar as metodologias projetuais e os requisitos para o desenvolvimento de móveis acessíveis, tendo como estudo de caso os armários para guarda roupa, baseado nos princípios do Design Universal de modo a garantir a acessibilidade destes.

Palavras-chave: Design universal; metodologia de projeto; acessibilidade. 


\section{INTRODUÇÃO}

Acessibilidade é a condição fundamental e imprescindível a todo e qualquer processo de inclusão social, e se apresenta em múltiplas dimensões, incluindo aquelas de natureza operacional, física, tecnológica, informacional, comunicacional, linguística e pedagógica, dentre outras. Para que exista acessibilidade é preciso a identificação e eliminação das barreiras que irão impedir que os seres humanos, portadora de deficiência ou com mobilidade reduzida, realizem e exerçam as atividades na sociedade, dando autonomia nos espaços, mobiliários e equipamentos urbanos, nas edificações, serviços de transporte e dispositivos, sistemas e meios de comunicação e informação. De acordo com Piardi et al (2012) o direito a igualdade a todos os cidadãos, está garantido na Constituição Brasileira de 1998, essa garantia inclui o acesso à moradia, ao trabalho e a serviços essenciais como educação e saúde para todas as pessoas, independentemente do sexo, idade, cor, credo, condição social ou deficiência, além da promoção de mudanças no ambiente físico, para atingir melhores condições de acessibilidade espacial e permitir a todas as pessoas a realização de atividades desejadas.

Essa discussão de garantia dos direitos da pessoa com deficiência, não é uma questão recente, no final da Segunda Guerra Mundial houve uma conscientização da participação social. Nos anos 60 essa mobilização se fortaleceu e em 1981 a ONU Organização das Nações Unidas ONU - decretou que esse era o Ano Internacional das Pessoas, Portadoras de Deficiência (AIPPD). Em 1970 surge o conceito de Design Universal, esta concepção está relacionado a sociedade inclusiva independente de idade, habilidade, capacidade físico-motora ou situação sócio-econômica, considerar todas as possibilidades de uso.

Segundo o Censo do IBGE, realizado em 2010, 45,6 milhões de pessoas possui algum tipo de deficiência, cerca de $23,9 \%$ da população brasileira. Em 2000, a Constituição Brasileira exigiu por lei mudanças no ambiente físico para atingir melhores condições de acessibilidade especial para portadores de deficiência ou mobilidade reduzida, sendo promulgadas no decreto no 596 de Dezembro de 2004 no 10.048 e no 10.098.

Com esta premissa questiona-se como propósito norteador da pesquisa, como é abordada a acessibilidade no projeto de móveis sob medida? É possível o projeto e execução de armários para guardar roupa acessível e universal? Objetiva-se então, como resultado inicial a ser abordado neste artigo, apontar as metodologias projetuais e os requisitos para o desenvolvimento de móveis acessíveis, tendo como estudo de caso os armários para guarda roupa, baseado nos princípios do Design Universal de modo a garantir a acessibilidade destes.

De acordo com Reis et. al. (apud ALVES, 2014), projetos que não seguem o Conceito de Design Universal podem não somente impedir ou desencorajar o acesso e o uso por pessoas com deficiência física ou cognitiva, mas também podem aumentar o risco de acidentes. Assim como reconhecer a importância da utilização do conceito do Design Universal para a acessibilidade é também reconhecer que a metodologia do projeto em design é uma ferramenta indispensável.

\section{DESIGN UNIVERSAL}

A utilização de um método para o desenvolvimento de um móvel é de extrema importância. Os resultados obtidos pelos meios empregados para obter dados e 
conclusões acerca do problema do espaço residencial e o móvel que irá se inserido, como também os novos modos de vida contemporânea e as características e rotina das pessoas que irão usufruir daquele espaço. O conceito de Design Universal está relacionado ao conceito de sociedade inclusiva focado em produto, serviços e ambientes para serem usados pelo maior número de pessoas independente de idade, habilidade ou situação sócio econômica.

Ron Mace Arquiteto e Designer norte-americano cunhou o conceito de Design Universal em 1970. Mace era cadeirante, por conta da Poliomielite, doença que teve na infância. Para ele o projeto de início deve considerar as diversidades de necessidades humanas, uma concepção que atenda diferentes deficiências sem que seja necessário uma adaptação ou um projeto exclusivo para esse tipo de público. Com a finalidade que projetos conciliem as diversas e complexas necessidades em um só projeto, o Design Universal projeta espaços, equipamentos, objetos e ações que reconheçam que as pessoas são naturalmente diferentes.

O Design Universal é definido em sete princípios, sendo uma teoria de projeto e uma fonte de avaliação seja ele gráfico, produto, arquitetônico ou organizacional.

Uma equipe do the center for universal design (Centro para o Design Universal da Universidade Estadual da Carolina do Norte - EUA), como parte do seu projeto "Estudos para Incrementar o Desenvolvimento do Design Universal" Dirigiu uma sucessão de avaliações para determinar as características de funcionamento e elementos de produtos de consumo, espaços arquitetônicos e elementos de construção, para que sejam usados na maior extensão de pessoas possíveis, sem a obrigação de adaptação ou desenho especializado. The center for universal design, formou um grupo de arquitetos, designers de produto, engenheiros e pesquisadores de concepção ambiental, determinando sete princípios do Desenho Universal. Estes princípios são para um melhor direcionamento das disciplinas de design para que sejam aplicadas na analise de projetos existentes, processos criativos e instruir designers e consumidores sobre as propriedades dos produtos e ambientes mais aproveitáveis.

Os princípios do Desenho Universal são apresentados, na seguinte forma:

a) Uso Equitativo (com igualdade): produtos e ambientes devem ser planejados para serem utilizados por pessoas com diferentes habilidades e características, assim evitando marginalizar qualquer tipo de usuário;

b) Flexibilidade no Uso: produtos e ambientes devem ser flexíveis, onde há a possibilidade do usuário escolher a forma de utilização, favorecendo as habilidades pessoais e preferências e ritmo;

c) Uso Simples e Intuitivo: $O$ design deve ser compreensível, independentemente da experiência do usuário, o entendimento, os conhecimentos linguísticos, ou nível de absorção atual;

d) Informação Perceptível: $O$ design direciona de forma eficiente a informação necessária para o usuário, independentemente das suas condições ambientais ou habilidade de percepção;

e) Tolerância ao Erro: $O$ design reduz o risco de acidentes e as consequências adversas de ações. São advertências ou métodos de prevenção para acidentes, para diminuir o risco de acidentes involuntários ou imprevistos; 
f) Baixo Esforço Físico: O design deve ser usado de forma eficiente e satisfatória e com um mínimo de fadiga. Dispor de formas eficientes para evitar fadiga no usuário tornando aquela atividade exercida confortável;

g) Tamanho e Espaço para Aproximação e Uso: O Designer deve estabelecer dimensões para que o ambiente e espaço, sejam apropriados o acesso, alcance, manipulação e uso, independentemente do tamanho do corpo do usuário, postura ou mobilidade. Proporcionar uma visão clara e livre dos elementos dos elementos importantes, independentemente da posição do usuário. Que todo o tipo de usuário, (criança, idoso, pessoas com deficiência física, etc.) possa alcançar e acomodar de forma confortável, todos os tipos de constituintes a seu redor.

\section{METODOLOGIAS DE PROJETO EM DESIGN}

De acordo com Cardoso et al (2013), "metodologia é o estudo de métodos, técnicas e ferramentas, e de suas aplicações à definição, organização e solução de problemas teóricos e práticos". Para elas, o método garante o desenvolvimento do projeto através da utilização de técnicas que exploram o processo criativo, lógico e avaliam o controle de tempo. Conforme Cardoso e Picolei (2013) este planejamento estabelece metas do desenvolvimento e controle operacionais, etapas de analise, criação e geração de alternativas, verificação e especificações refinadas de detalhadamente. Assim prevendo prazos, evitando erros humanos, compreender e definir com eficácia um problema.

Segundo Munari (1981), não se pode projetar sem um método [...] O método projetual não é mais do que uma série de operações necessárias, dispostas por ordem lógica, ditada pela experiência. $O$ seu objetivo é o de se atingir o melhor resultado com o menor esforça.

Foram estudas diversas metodologias projetuais, aplicadas ao desenvolvimento de mobiliário, entre elas as metodologias consagradas pelos autores:

- Bruno Munari, que propõe da decomposição do problema e o caminho necessário para chegar à solução;

- $\quad$ Flávio Antero, com o Método Aberto de Projeto, que é uma metodologia flexível e adaptável por ser aberta, possibilitando a inversão de outras metodologias e a construção de um método próprio, bem como acrescenta a diversidade de exercícios e desafios necessários ao projeto;

- A metodologia de desenvolvimento integrado de produtos - DIP, proposta por Forcellini que acredita que o processo de desenvolvimento de produto assume uma importância fundamental para a competitividade das indústrias no mercado, e engloba a elaboração de produtos, baseando-se nos requisitos de qualidade, custo e tempo.

Com o objetivo que se perceba a melhor metodologia que organize e gerencie o desenvolvimento de um armário de guarda roupa projetado para cadeirantes, foi elaborado um quadro comparativo das fases das metodologias do projeto em Design, dos autores abordados neste trabalho. 
Quadro 1 - variáveis antropométricas para dimensionamento de armários para guardar roupa

\begin{tabular}{|c|c|c|c|c|c|c|c|c|c|c|c|c|}
\hline \multirow{4}{*}{$\begin{array}{c}\text { AUTORES } \\
\text { Bruno } \\
\text { Munari }\end{array}$} & \multicolumn{12}{|c|}{ FASES } \\
\hline & \multicolumn{6}{|c|}{ ELABORAÇAO DO PROJETO } & \multicolumn{6}{|c|}{ IMPLEMENTAÇAO } \\
\hline & \multicolumn{3}{|r|}{1} & \multirow{2}{*}{$\begin{array}{c}2 \\
\text { Coleta de } \\
\text { dados }\end{array}$} & \multirow{2}{*}{$\begin{array}{c}3 \\
\begin{array}{c}\text { Analise de } \\
\text { dados }\end{array}\end{array}$} & \multirow{2}{*}{ Criatividade } & \multicolumn{3}{|c|}{5} & \multicolumn{3}{|c|}{6} \\
\hline & Problema & $\begin{array}{l}\text { Definiçăo do } \\
\text { problema }\end{array}$ & $\begin{array}{l}\text { Componentes } \\
\text { do problema }\end{array}$ & & & & $\begin{array}{l}\text { Materias e } \\
\text { tecnologias }\end{array}$ & Experimentaçăo & Modelo & Verificação & $\begin{array}{l}\text { Desenho } \\
\text { construtivo }\end{array}$ & Soluçăo \\
\hline Forcellini & \multicolumn{3}{|c|}{ Definição do produto - Ideia } & \multicolumn{3}{|c|}{$\begin{array}{l}\text { Projeto de produto- documentaçáo } \\
\text { do produto } \\
\text {-Projeto informacional } \\
\text {-Projeto conceitual } \\
\text {. Projeto preliminar } \\
\text {.Projeto detalhado }\end{array}$} & \multicolumn{3}{|c|}{ Projeto de produto - produto } & \multicolumn{3}{|c|}{$\begin{array}{l}\text { Lançamento e acompanhamento } \\
\text { de produto - mercadoria }\end{array}$} \\
\hline $\begin{array}{l}\text { Flávio } \\
\text { Antero }\end{array}$ & $\begin{array}{l}\text { Problema do } \\
\text { projeto }\end{array}$ & \multicolumn{2}{|c|}{$\begin{array}{l}\text { Pré-concepçáo } \\
\text {-Analise do problema } \\
\text {-Planejamento do problema } \\
\text {-Atributo ao produto }\end{array}$} & \multicolumn{3}{|c|}{$\begin{array}{l}\text { Concepçáo } \\
\text { - Geraçăo de alternativas } \\
\text { - Seleção de alternativas } \\
\text { - Caminhos criativos }\end{array}$} & \multicolumn{3}{|c|}{$\begin{array}{l}\text { Pós-concepçáo } \\
\text {-Componentes do problema } \\
\text { • Processo produtivo } \\
\text {-Mercado }\end{array}$} & \multicolumn{3}{|c|}{$\begin{array}{l}\text { Desdobramentos } \\
\text { auxiliares }\end{array}$} \\
\hline
\end{tabular}

Fonte: elaborado pelo autor, com base na pesquisa realizada.

\section{PROBLEMATIZAÇÃO DO SISTEMA HOMEM X TAREFA X MÁQUINA}

O guarda roupa é um móvel utilizado para condicionar roupas e objetos pessoais que são utilizados constantemente pelos indivíduos. Por essa razão as dimensões do produto devem estar de acordo com o as necessidades do usuário principalmente cadeirantes, para exerçam a atividade com mais independente, conforto, eficiência e segurança.

Para compreensão da interação do produto com os usuários cadeirantes tornou-se necessária a análise da tarefa e o detalhamento dos problemas observados no uso do mobiliário. De acordo com análise da tarefa foi observado que o guarda roupa necessita de ajustes para um melhor conforto e segurança no condicionamento dos objetos, uma vez que, o cadeirante tem uma altura e alcance limite para realizar algumas atividades.

Dos problemas observados, o mais explícito durante o manuseio de roupas e objetos formam os interfaciais/posturais, físico-ambientais e de acessibilidade. Algumas tarefas como alcançar a arara ou abaixar para pegar um utensílio na gaveta ou na prateleira podem causar tensões musculares localizadas como no pescoço e costas, agravando os problemas do cadeirante. Estes movimentos não atendem os requisitos ergonômicos, já que exigem esforços fora dos limites do corpo bem como manobras com a cadeira, ainda mais dificultada pelo espaço disponível nos ambientes. Para um melhor esclarecimento dos problemas entre a tarefa, homem e máquina, no quadro 1 aprofunda-se problema, como orienta Moraes (1998, apud PEQUINI, 2007). 
Quadro 1 - Problematização baseada na análise da tarefa

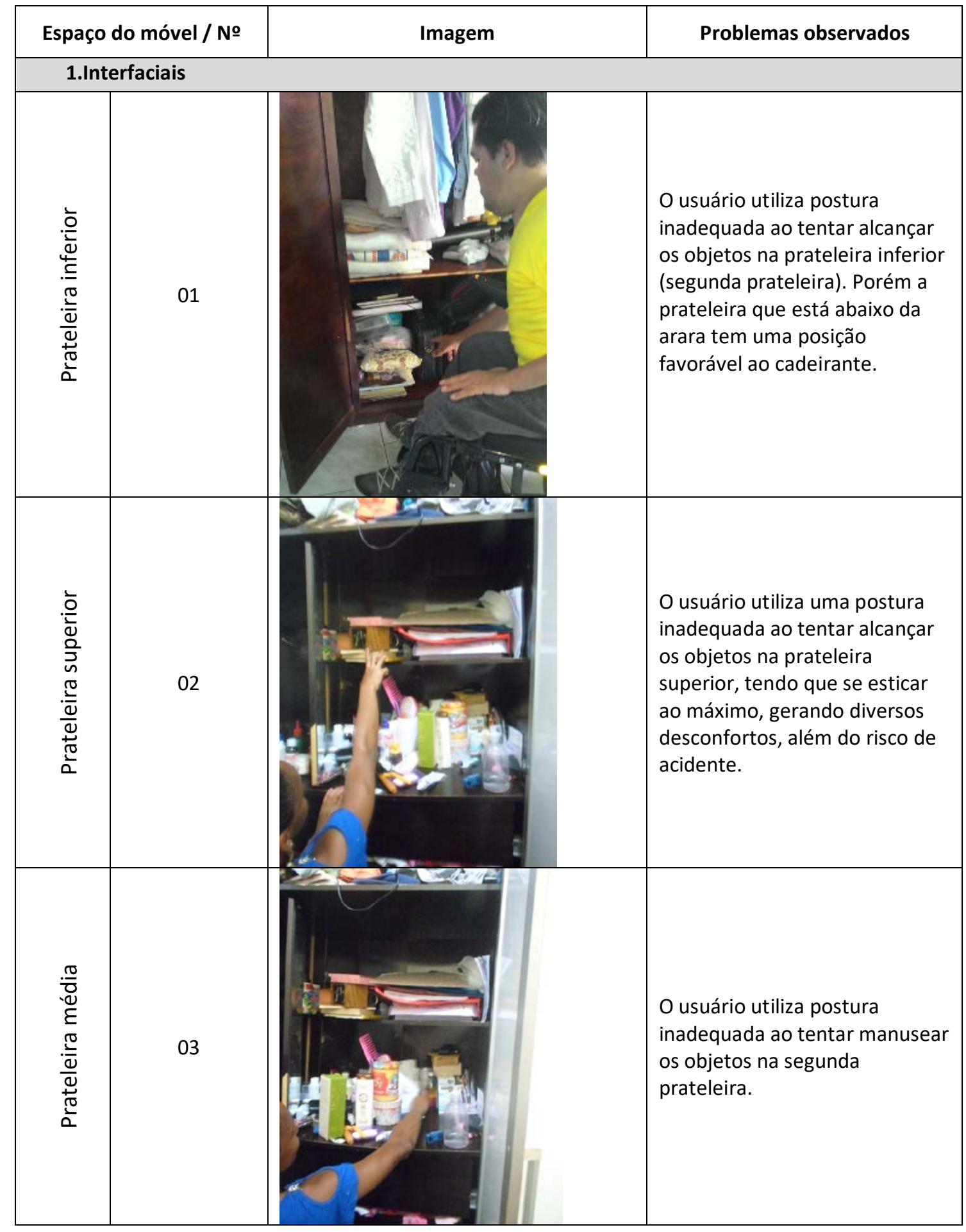




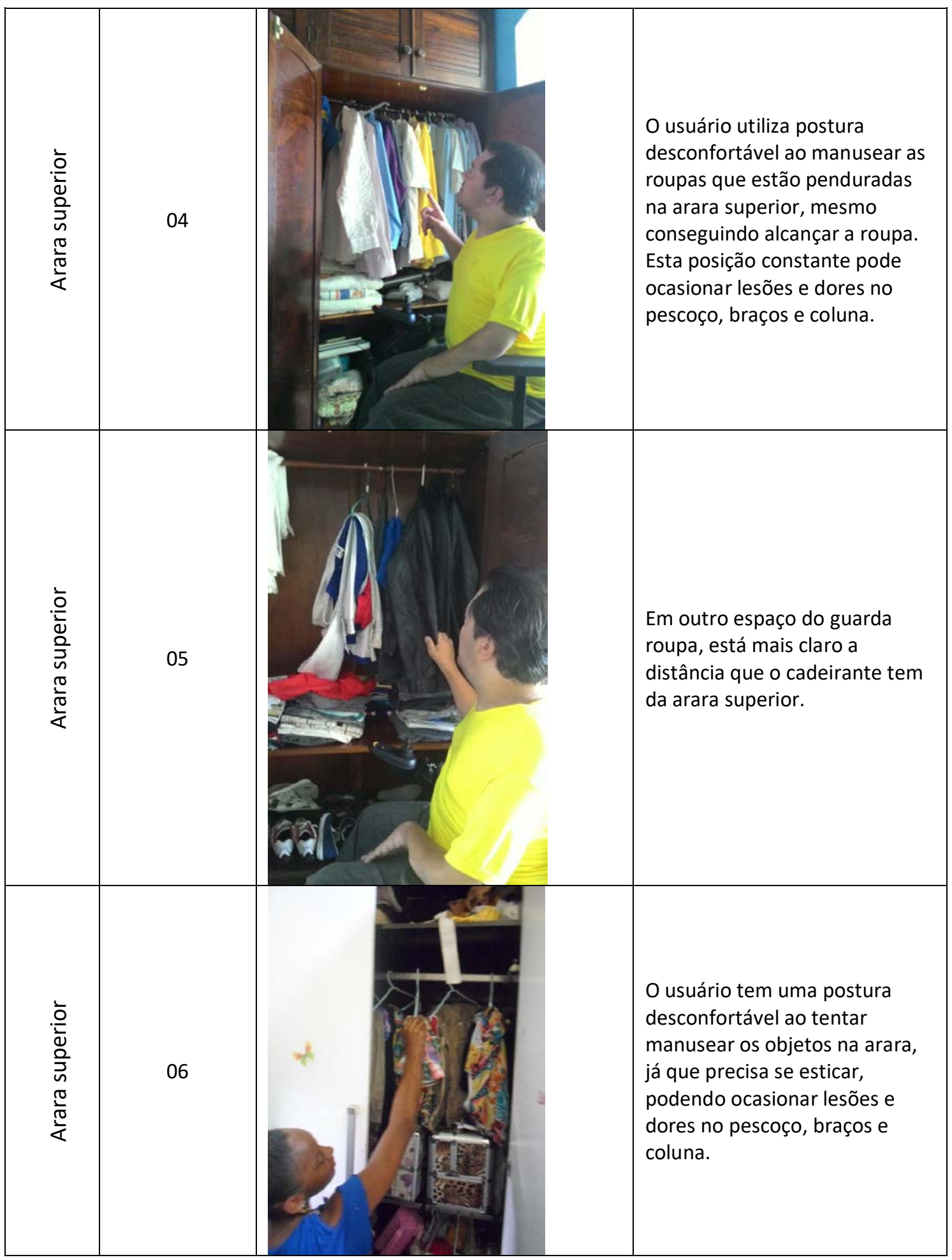




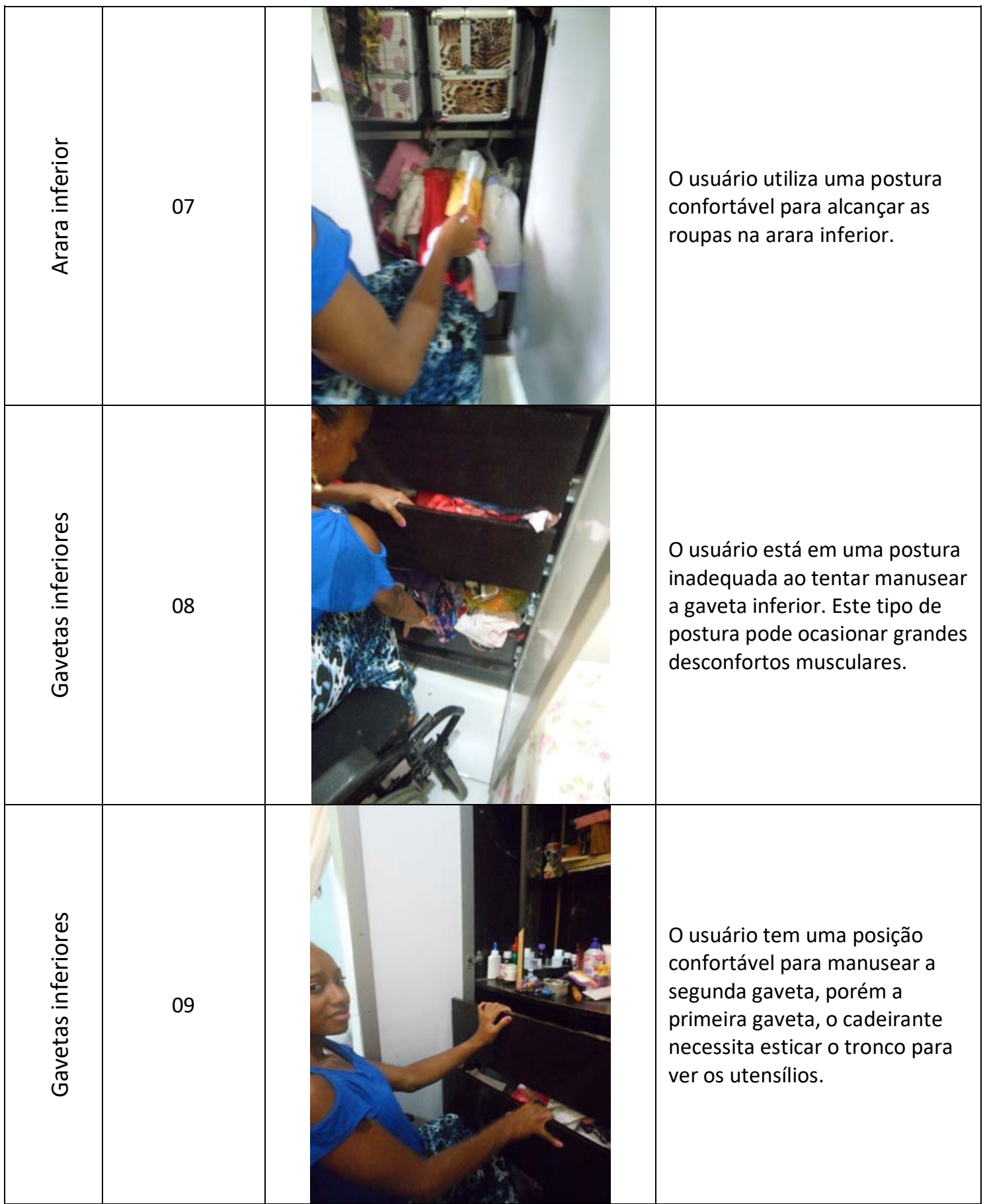




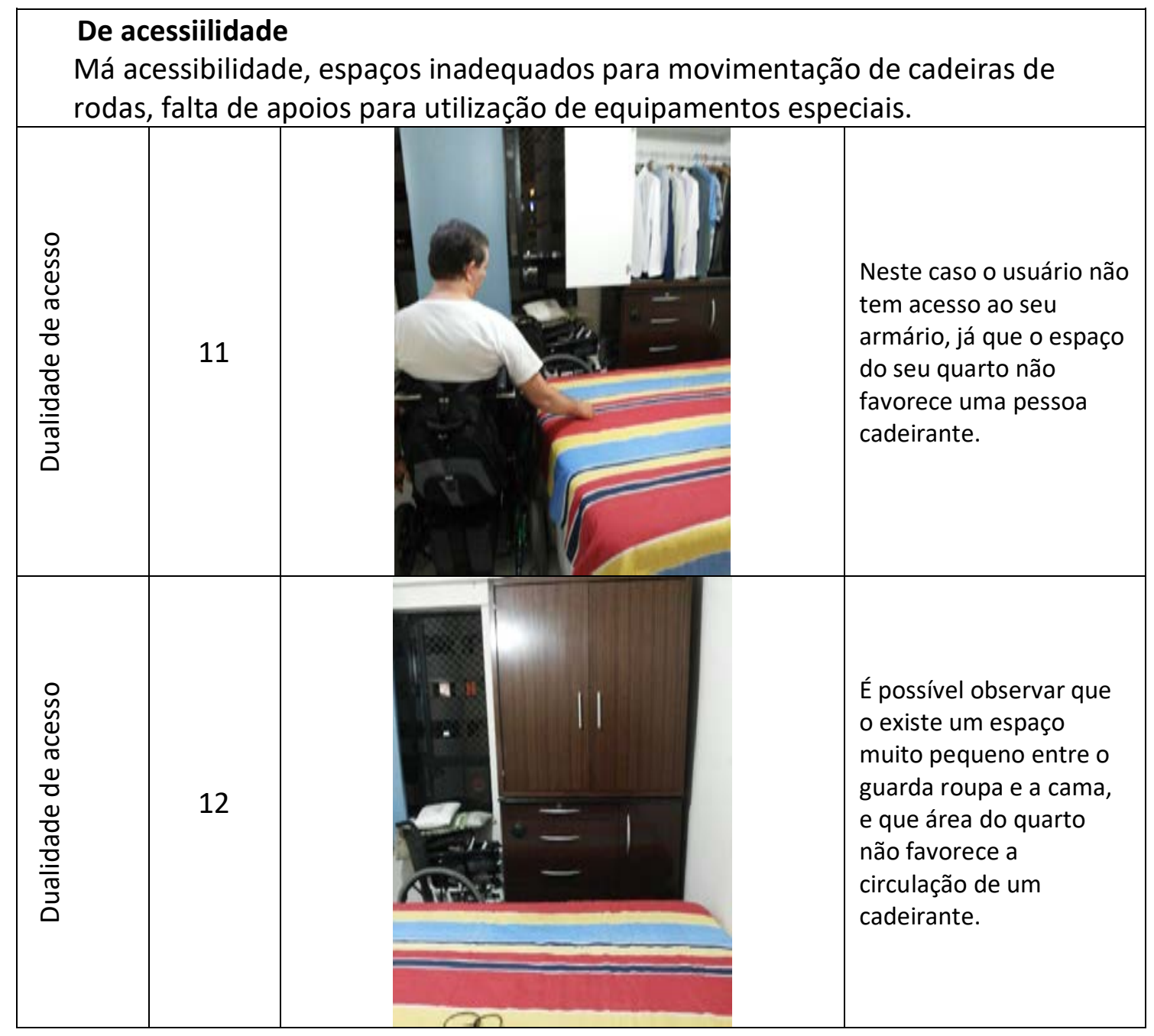

Fonte: elaborado pelo autor, com base na pesquisa realizada.

\section{LEVANTAMENTO DE DADOS ANTROPOMÉTRICOS PARA O DIMENSIONAMENTO DE ARMÁRIOS DE GUARDAR ROUPA PARA CADEIRANTES}

Foram levantados as variáveis antropométricas para dimensionamento de armários para guardar roupa acessíveis considerando os percentis 5,0 da mulher e 95,0 do homem de forma a atender a $90 \%$ da população usuária.

Quadro 2 - variáveis antropométricas para dimensionamento de armários para guardar roupa

\begin{tabular}{|l|l|c|c|}
\hline $\begin{array}{c}\text { Variáveis } \\
\text { dimensionais }\end{array}$ & $\begin{array}{c}\text { Variáveis } \\
\text { antropométricas }\end{array}$ & $\begin{array}{c}\text { Percentil } \\
\text { Mulher 5 } \\
\text { Homem 95 }\end{array}$ & $\begin{array}{c}\text { Dimensões } \\
(\mathrm{cm})\end{array}$ \\
\hline $\begin{array}{l}\text { Profundidade } \\
\text { do armário }\end{array}$ & $\begin{array}{l}\text { Comprimento } \\
\text { da articulação do } \\
\text { ombro até a } \\
\text { extremidade do } \\
\text { dedo médio na } \\
\text { postura sentada }\end{array}$ & Mulher 5 & 66,0 máx. \\
\hline
\end{tabular}




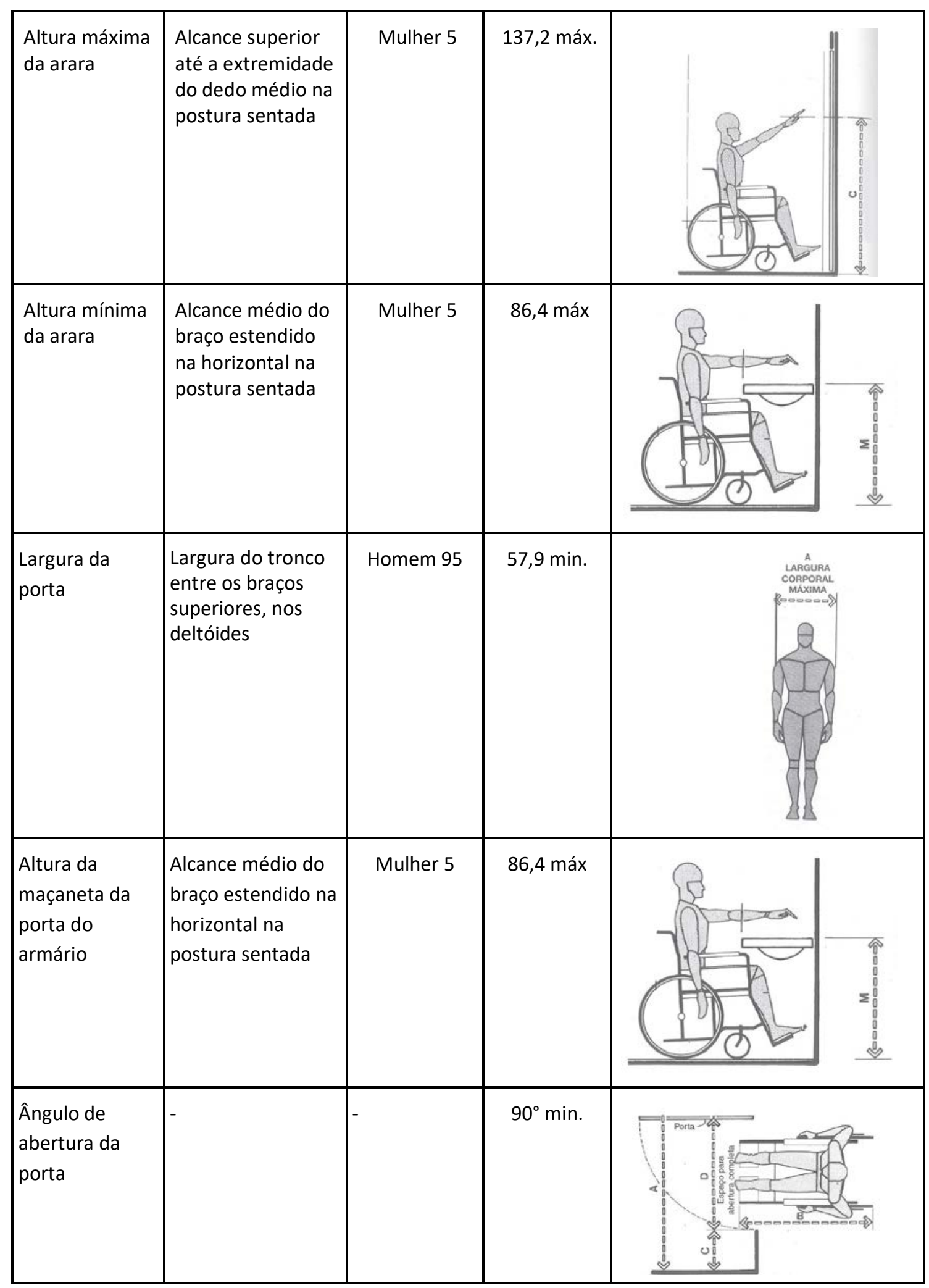




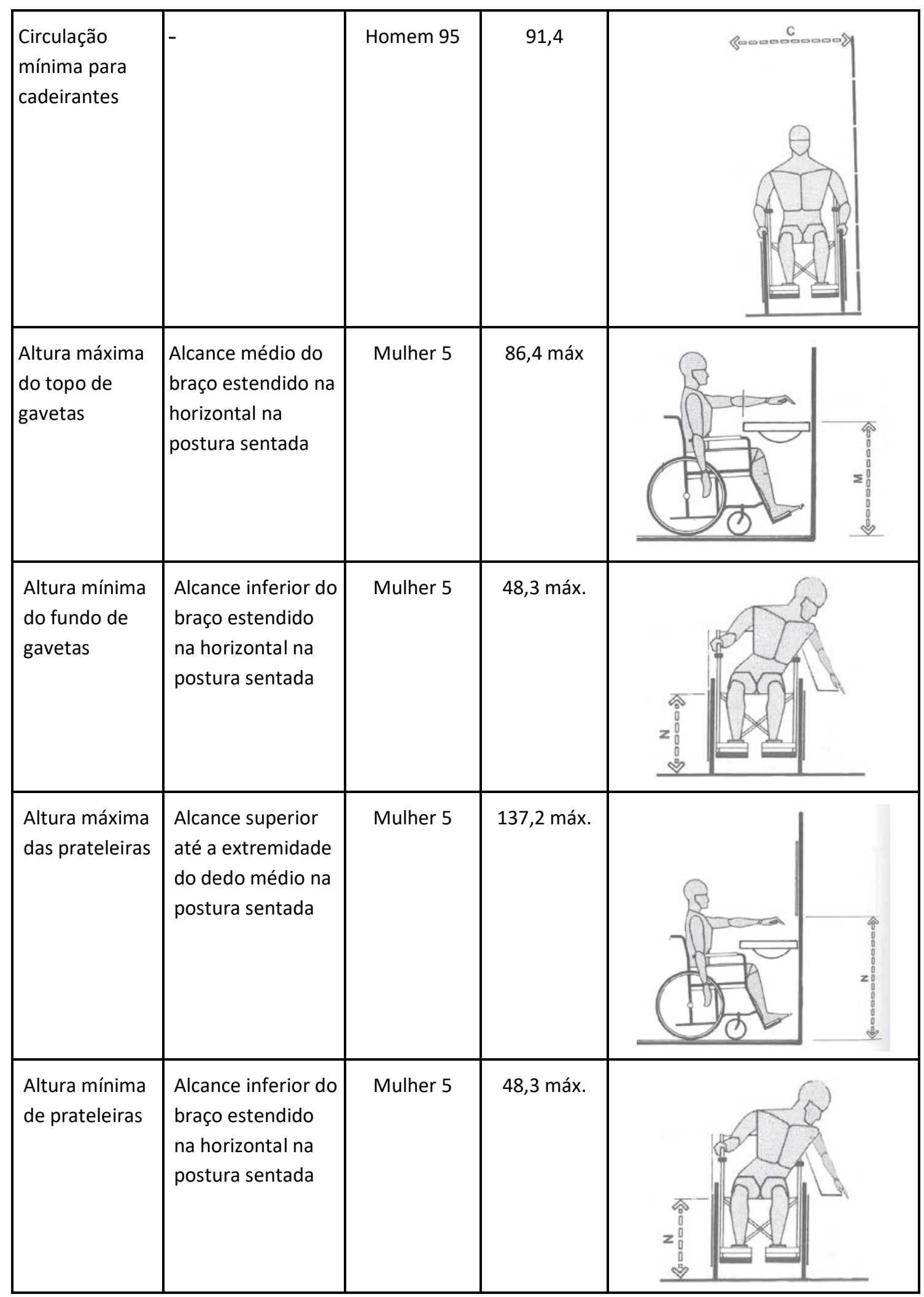




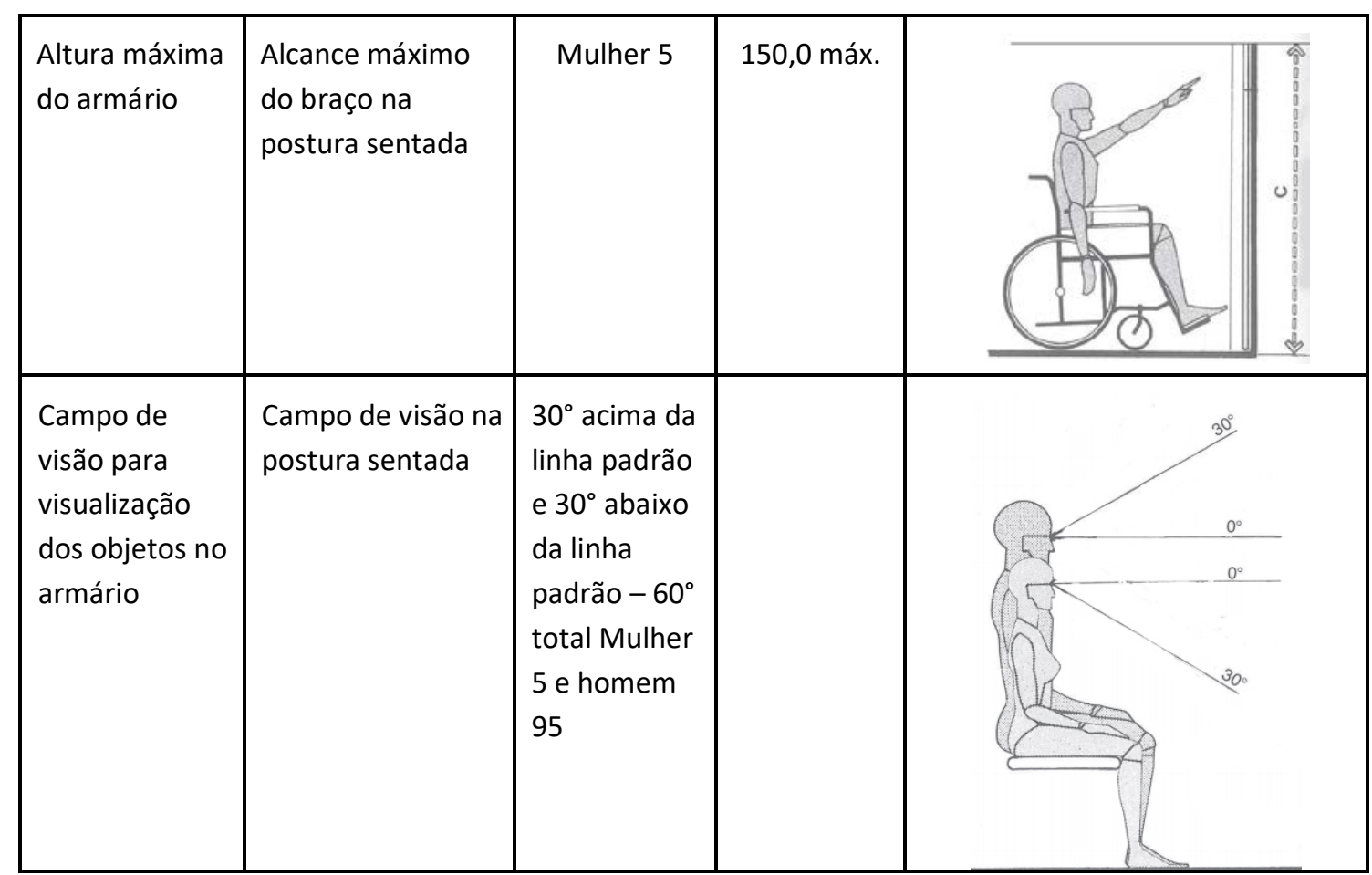

Fonte: elaborado pelo autor, com base na pesquisa realizada. Imagens de Panero, 2003.

\section{CONCLUSÃO}

Com base na analise feita até o momento, as pessoas com deficiência adquiriram grandes conquistas a partir da década de 90 , tanto no campo de pesquisa como em leis que garante o direito de acessibilidade, identificando e eliminando as diversas barreiras que impeçam a realização e exerçam as atividades no corpo social, a fim de garantir uma sociedade democrática. Portanto a antropometria e a ergonomia, sob o vetor do design, trazem estudos de medidas físicas do corpo humano e sua relação com o trabalho originando resultados que garantam as modificações nos diversos âmbitos sociais dando autonomia nos espaços, mobiliários e equipamentos urbanos, nas edificações, serviços de transporte e dispositivos, sistemas e meios de comunicação e informação.

Considera-se para tanto, de modo conclusivo e pautado nos limiares da pesquisa, que a aplicação adequada das práticas projetuais, associadas aos princípios do Design Universal e o emprego de requisitos antropométricos, permitirão o desenvolvimento de mobiliário acessível e adaptado à inclusão de todas ou da maioria das pessoas ao uso do mesmo. No estudo aqui proposto, os requisitos antropométricos delimitados deverão, exclusivamente ser aplicados ao projeto de guarda roupas. No entanto, cabe ao designer, partindo do mesmo princípio aqui exposto, estabelecer parâmetros projetuais adequados ao uso no que tange a relação humanoXtarefaXmáquina.

A pesquisa encontra-se em fase de validação, onde os dados conclusivos serão aplicados ao desenvolvimento de um protótipo para avaliar e consolidar a pertinência dos dados apresentados.

Sugere-se como propostas futuras a continuidade da pesquisa no âmbito de estudo de requisitos para outros mobiliários, à propor uma ambiente mobiliado inclusivo; bem como o estudo de aplicação dos parâmetros citados à indústria 
moveleira. Aqui também propõe-se o uso do resultado da pesquisa, bem como da sua continuidade, pautada na produção industrial com valor acessível à maioria.

\section{REFERÊNCIAS}

ABNT NBR 9050. Acessibilidade a edificações, mobiliário, espaços e equipamentos urbanos. Rio de Janeiro, 2004.

ANTHERO, Flávio. Método aberto de projeto para uso no ensino de Design Industrial. Revista Design em Foco v. III no1. Salvador, Jan./Jun. 2006.

ASSOCIATES, Henry Dreyfuss, TILLEY, Alvinr. As Medidas do Homem e da Mulher: Fatores Humanos em Design. Editora Bookman, 2005.

BONSIEPE, Gui. Design como prática de projeto. São Paulo: Editora Blucher, 2012.

DEVIDES Maria T.C. Design, Projeto e Produto: 0 desenvolvimento de móveis nas indústrias do Pólo Moveleiro de Arapongas, PR. Bauru, SP, 2006.

DISCHINER Marta, ELY Vera, PIARDI Sonia. Promovendo acessibilidade espacial nos edifícios públicos: Programa de Acessibilidade às Pessoas com Deficiência ou Mobilidade Reduzida nas Edificações de Uso Público. Florianópolis, 2012. (Ministério Público Do Estado De Santa Catarina Procuradoria Geral De Justiça - Centro de Apoio Operacional dos Direitos Humanos e Terceiro Setor).

FORCELLINI Fernando. Projeto Conceitual. Capitulo II: Processo de projeto. Santa Catarina, 2003.

GIL, Antonio Carlos. Como elaborar projetos de pesquisa. São Paulo: Editora Atlas, 1987.

LIMA, João Ademar de Andrade. Arquitetura de Interiores. Facisa. Paraíba, 2005.

MARIÑO, Suzi e COUTO, Rita. Como classificar pesquisa. Salvador, 2003. MORAES, Dijon De. Metaprojeto o design do design. São Paulo: Editora Blucher, 2010.

MORAIS, Anamaria. Aplicação de dados antropométricos dimensionamento da interface homem-maquina. Dissertaçãode mestrado. Rio de Janeiro:

COPPE/UFRJ,1983.

MUNARI, Bruno. Das coisas nascem coisas. São Paulo: Editora Martins Fontes, 1998.

PANERO, Juliua MARTIN, Zelnik. Dimensionamento Humano para Espaços Interiores: Um Livro De Consulta e Referência Para Projetos. Editora: GGbrasil.

Ano: 2003.

PINA, Suzana. Avaliação do uso de recursos tecnológicos na etapa de concepção de produtos industriais em um escritório de projetos. Faculdade de Tecnologia SENAI CIMATEC Programa De Pós-Graduação Em Gestão E Tecnologia Industrial. Salvador, 2011.

RODRIGUES, José Wasth. Uma história do mobiliário brasileiro. 70 Congresso Brasileiro de Pesquisa e Desenvolvimento em Design. Prananá, 2006. 
ALVES Fernanda Sales. Iluminação Universal: A Ergonomia e o Design Universal aplicados ao projeto lumínico em sala de aula. Universidade Federal Da Bahia, Escola De Belas Artes. Salvador, 2014.

CARDOSO, Cilene. PICOLI Julia. Metodologia de projeto de Bruno Munari aplicada ao design de superfície de moda. $9^{\circ}$ Colóquio de Moda. Fortaleza, 2013.

FRANCISCO, Paulo e MENEZES Alexandre. Design Universal, acessibilidade e espaço construído. Belo Horizonte:, 2011.

LEONARDO, Neymar. Designer, especialista em Design de produto. Atua com desenvolvimento de produtos no Campus Integrado de monufatura e Tecnologia SENAI CIMATEC, nos seguimentos de desenvolvimento integrado de produto, ergonomia e Design estratégico.

Acessbilidade. Disponível em: <http://acessibilidade-

portugal.blogspot.com.br/2012/09/design-universal-1-ideia-7-principios.html> Acesso em 06 de abril de 2016

Design Universal. Disponível em <http://www.includible.net/artigos/designuniversal1-definicao-7-principios/> acesso em 06 de abril de 2016.

Design Universal. Disponível em Revista Cliche.

<http://www.revistacliche.com.br/2013/04/o-design-universal/. Acesso em:

07/07/2015.

História do mobiliário. Disponível em: Essenciais Móveis.

<http://www.essenciamoveis.com.br/blog/2012/09/historia-dos-moveis-aideiaprincipal-da-mobilia/> Acesso em 05/07/2015.

Princípios do Design Universal. Disponível em Quantu Design.

$<$ http://www.quantumdesign.com.br/7-principios-design-universal/> Acesso em 06/07/2015.

Instituto Brasileiro de Geografia e Estatística. Dados sobre Pessoa com deficiência no Brasil. 2010. Disponível em: <http://teen.ibge.gov.br/calendario-teen-

7a12/evento/1096-dia-internacional-das-pessoas-com-deficiencia.html>. Acesso em:

06 de Abril de 2016. 